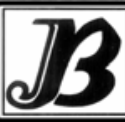

J. bio-sci. 18: 9-15, 2010

ISSN 1023-8654

http://www.banglajol.info/index.php/JBS/index

\title{
EGGPLANT SHOOT AND FRUIT BORER LEUCINODES ORBONALIS GUÉNEE MALE MOTH CATCH IN SEX PHEROMONE TRAP WITH SPECIAL REFERENCE OF LURE ELEVATION AND IPM
}

\author{
F Mazumder, M Khalequzzaman* \\ Department of Zoology, University of Rajshahi, Rajshahi 6205, Bangladesh
}

\begin{abstract}
Context: Female pheromone attracts the male eggplant shoot and fruit borer. The pheromone lure could be used in catching male adults to control this pest population in eggplant fields.

Objectives: To study the efficacy of sex pheromone (lure) on the male moth catch of eggplant shoot and fruit borer (ESFB) Leucinodes orbonalis Guenée, shoot and fruit destruction and fruit yield in the control, IPM operated fields and farmer's fields.

Materials and Methods: For pheromone trap operation the experiments were done in four sites of the Rajshahi City. For IPM strategy two sites were selected in Paba upozilla. Pheromone traps were operated with the lure combination of 100:1 of E11-16: Ac and E11-16: $\mathrm{OH}$. The trap consisted of a 3-liter capacity, 22-cm tall rectangular or round clear plastic container. A triangular hole is cut in any two opposite sides starting 3 to $4 \mathrm{~cm}$ from the bottom. The traps were randomly assigned in the study plots and installed with the help of bamboo stick. Sex pheromone trap height from ground level in the field was standardization for best trapping efficiency. For this traps were placed at $0.5 \mathrm{~m}$ and $1 \mathrm{~m}$ high above the ground in the field. In both cases control fields (without insecticide) of the same size were used in the experiments.

Results: The number of ESFB males in ten trap catches were 1.7 to 4.5 with a mean number of $3.26 \pm 0.32,8.49 \pm$ $0.36,5.20 \pm 0.24$ and $14.95 \pm 0.34 \mathrm{catch} /$ trap in the Fields $1,2,3$ and 4 respectively. The average moth catch per trap was $1.76 \pm 0.56$ and $4.54 \pm 0.94$ in the 0.5 and $1 \mathrm{~m}$ lure respectively. The damaged shoot was $19.34 \pm 2.31 \%$ at 0.5 $\mathrm{m}$ lure height, whereas at $1 \mathrm{~m}$ height no damaged shoot was recorded. A damaged fruit was recorded as 29.74 $\pm 1.87 \%$ and $14.47 \pm 2.29 \%$ with the fruit yield in $q /$ ha was $176.58 \pm 6.38 \%$ and $232.56 \pm 6.63 \%$ at the 0.5 and $1 \mathrm{~m}$ lure height plots respectively. When no trap was operated in the eggplant fields the shoot damage, fruit damage and fruit yield were $3.48 \%, 31.15 \%$ and $13.70 \mathrm{~kg} / 100 \mathrm{~m}^{2}$ respectively in the non-IPM blocks. On the otherhand they were $1.56 \%, 10.66 \%$ and $27.54 \mathrm{~kg} / 100 \mathrm{~m}^{2}$ in the IPM blocks respectively.

Conclusion: The sex pheromones which have been extensively studied and already are in management programmes should be fine tuned to improve their efficacy in totality in an Integrated Pest Management Programme on the basis of feed back from the extension workers, and farmers.
\end{abstract}

Key words: pheromone, Eggplant, Leucinodes orbonalis, IPM

\section{Introduction}

Eggplant is one of the most important vegetables in South and South-East Asia. It is grown on over 678,000 ha, which is about $37 \%$ of the world eggplant area, with a production of 10.50 million ton (FAO 2007). Among the many pest species, the eggplant fruit and shoot borer (ESFB), Leucinodes orbonalis Guenée, is the most destructive (Alam and Sana 1964, Purohit and Khatri 1973, Kuppuswamy and Balasubramanian 1980, Allam et al. 1982). The larvae bore inside tender shoots and stunt plant growth. More severe economic damage comes from larvae feeding inside fruits, making even slightly damaged fruit unfit for human consumption. The yield loss could be as high as 70\% (Krishnaiah 1980, Islam and Karim 1991, Dhandapani et al. 2003) and may goes upto 90\% as reported in India (Kalloo 1988) and similar losses are also common in Bangladesh (Ali et al. 1980). Despite the importance of eggplant and severity of ESFB problem, the management practices to combat ESFB are still limited to frequent sprays of toxic chemical pesticides (Kabir et al. 1996). A survey conducted in Bangladesh in 2002 revealed a frequency of 120 sprays in one season (Rashid et al. 2003).

* Corresponding author E-mail: kzaman@ru.ac.bd 
In the context of damage for ensuring food safety and minimization of severity, environmental hazards, appropriate management practice for ESFB incorporating different methods as needed and ought to be devised consistent with modern pest management. The researchers have been trying combination of various components of the IPM package such as cultural, mechanical, pheromone, chemical etc. for the control of brinjal shoot and fruit borer (FAO 2003, Sasikala et al. 1999, Maleque et al. 1998). Since pesticides impart undesirable effects on the environment and human health, several countries, including India, have introduced integrated pest management (IPM) approaches that are based on restoring the natural balance between pests and their predators in ecological systems. Most of such IPM approaches are pest specific and influenced by host-plant relationships and the crop ecosystem.

Sex pheromones are important component of IPM programmes and they are mainly used to monitor as well as mass-trap the male insects. Zhu et al. (1987) identified (E)-11-hexadecenyl acetate (E11-16: Ac) as the major component of ESFB sex pheromone in China. Attygalle et al. (1988) and Gunawardena et al. (1989) also identified the presence of this compound from the sex pheromone glands of ESFB in Sri Lanka. In addition, they have also identified trace quantities of (E)-11-hexadecen-1-ol (E11-16:OH). In order to reduce the pesticidal load in the environment and to be abreast with sustainability, certain behavioural chemicals could be harnessed. Such an endeavour is the use of sex pheromones. This dynamic and paradigm shift in management strategies satisfies all the bio-safety concern as well as playing a pivotal role in combating insect pests of high-value and damage sensitive crops. In the present investigation an endevour has been made to study the efficacy of sex pheromone (lure) on the male moth catch of ESFB, shoot and fruit destruction and fruit yield in the control, IPM operated and farmer's fields.

\section{Materials and Methods}

Experimental sites and field preparation: For pheromone trap operation the experiments were done in four sites of the Rajshahi City. The intensive study was made in the fields selected within the campus of University of Rajshahi; one vegetable garden in the residential area (Field 1); one at the experimental fields (Field 2) of the Department of Agronomy and Agricultural Extension, and the other was in the Field Laboratory (Field 3) of the Institute of Biological Sciences. Farmer's field (Field 4) was located at the Padma Residential Area - $2 \mathrm{~km}$ away from the University of Rajshahi.

Cow dung and other chemical fertilizer were applied as recommended by Rashid (1999) for brinjal cultivation @ 15 tons of cow dung and 115,72 and $75 \mathrm{~kg}$ of N, $\mathrm{P}_{2} \mathrm{O}_{5}$ and $\mathrm{K}_{2} \mathrm{O}$, respectively per hectare. The half of cow dung and $\mathrm{P}_{2} \mathrm{O}_{5}$ were applied as basal dose during land preparation. The remaining cow dung, $\mathrm{P}_{2} \mathrm{O}_{5}$ and onethird of $\mathrm{K}_{2} \mathrm{O}$ was applied in the pits at transplanting of brinjal seedlings. The entire dose of $\mathrm{N}$ and the rest of $\mathrm{K}_{2} \mathrm{O}$ were applied as top dressing. The first top dressing of urea (one third) was made at 15 days after transplanting. One-third of $\mathrm{N}$ and one-third of $\mathrm{K}_{2} \mathrm{O}$ were applied at the time of flower initiation and rest of urea and MP at the time of fruit initiation were applied to keep the plants at normal growth, development and production. The whole field was divided into three blocks of equal size having $2 \mathrm{~m}$ space between the blocks and each block was again sub-divided into 10 plots $(3 \mathrm{~m} \times 3 \mathrm{~m})$ with $2 \mathrm{~m}$ space between the plots. Fifteen pits were made in each plot at a distance of $100 \mathrm{~cm}$ between rows and $60 \mathrm{~cm}$ between pits on a row. Forty day old healthy seedlings ( $3 / 4$ leaf stage) were transplanted in the experimental plots. The others fields were managed as per the wish of the owner where cow dung, urea and MP were used. For experimental purpose all fields were kept insecticide spray free.

Pheromone trap: Pheromone traps were procured from Safe Agriculture (Bangladesh) Ltd., Dhaka. The lure was a combination of 100:1 of E11-16:Ac and E11-16:OH. This trap consists of a 3-liter capacity, 22-cm tall rectangular or round clear plastic container. A triangular hole is cut in any two opposite sides starting 3 to 4 $\mathrm{cm}$ from the bottom. Soapy water of 3 to $4 \mathrm{~cm}$ height is maintained inside the trap throughout the season. 
The pheromone lure is hung through the center of the lid inside the trap in such a way that it is 2 to $3 \mathrm{~cm}$ above the surface of the soapy water. The traps were randomly assigned in the study plots and installed with the help of bamboo stick. There were three replications in each plot. A $10 \mathrm{~m}$ distance between the traps was maintained.

Lure elevation and IPM strategy study: The height of sex pheromone lure in the trap from ground level was studied for standardization for best trapping efficiency. Lure in the trap at $0.5 \mathrm{~m}$ and $1 \mathrm{~m}$ was selected. In both cases control fields of the same size were kept under study as control plots. For IPM strategy two sites were selected in the Paba upozilla. The fields were under the control of eggplant farmers and an IPM Club organized by the local eggplant farmers under a project of Bangladesh Agriculture Research Institute. Site 1 having 5 plots each of $4 \mathrm{~m}^{2}$, where no management for the control of ESFB was operated. Site 2 having the same sized and number of plots where IPM was followed for the control of ESFB. IPM components followed were clipping of damaged shoots regularly, withholding the use of chemical pesticides thereby conserving natural enemies, and proper disposal of crop stubbles after uprooting. In both plots pheromone traps were operated.

Data collection: The trapped ESFB male moths were removed from the traps and their numbers were counted at three days interval and recorded. These traps placed at plant canopy heights were operated for 30 days. A total of 10 observations were made. Data were analyzed on the mean number of ESFB male moths per trap caught by three traps of each field. The comparative effectiveness of the treatments in reducing shoot and fruit borer infestation was evaluated on the basis of some pre-selected parameters. The total number of shoots and also the number shoots infested by the ESFB were recorded at weekly intervals from 5 plants of each plots.

\section{Results}

Pheromone trap catch of male ESFB moths: Results of the pheromone trap capture of male ESFB moths in different fields are presented in Table 1. It was observed that in Field 1 the number of ESFB for three trap catches was 1.7 to 4.5 with a mean number of $3.26 \pm 0.32$ male moths catch/trap. In Field 2 the number was 7.0 to 10.5 with a mean of $8.49 \pm 0.36$. In Field 3 the number was 4.2 to 6.4 with a mean number of $5.20 \pm$ 0.24 moths. In farmer's field (Field 4) the minimum number of ESFB for three trap catches was 13.0 and the maximum was 16.4 with a mean number of $14.95 \pm 0.34$ male moths/trap. The result shows that the population catch was the lowest in Field 1 and the highest was in Field 4. The analysis of variance shows that the mean male ESFB moths catch/trap within four fields differ significantly ( $F=251.52 ; P<0.01)$. The LSD value has been calculated as 1.257 and by comparing the value it could be seen that all means differ significantly among them.

Pheromone trap lure elevation: The average moth catch per trap, damaged shoot (\%), damaged fruit (\%) and fruit yield $(\mathrm{g} / \mathrm{ha})$ in two lure heights of eggplant plots are presented in Table 2. It was observed that the average moth catch per trap was $1.76 \pm 0.56$ and $4.54 \pm 0.94$ in 0.5 and $1 \mathrm{~m}$ lure respectively. The damaged shoots were $19.34 \pm 2.31 \%$ at $0.5 \mathrm{~m}$ lure height, whereas at $1 \mathrm{~m}$ height plots no damaged shoot was recorded. Damaged fruits were recorded as $29.74 \pm 1.87 \%$ and $14.47 \pm 2.29 \%$ with the fruit yield in q/ha was $176.58 \pm 6.38 \%$ and $232.56 \pm 6.63 \%$ at 0.5 and $1 \mathrm{~m}$ lure height plots respectively. Again in the fields where no pheromone trap was installed corresponding to the treated plots the damaged shoot was $34.39 \pm 2.65 \%$, damaged fruit was found as $47.27 \pm 2.38 \%$ and fruit yield in q/ha was $90.00 \pm 3.21$. Statistical analysis of the data shows that the t-value between lure heights are significant $(P<0.01)$ in case of average moth catch per trap, damaged fruit percentage and fruit yield when pheromone trap was operated. The t-value is also significant between trap operated and no trap operated fields in case of damaged shoot percentage of $0.5 \mathrm{~m}$ lure height, damaged fruit percentage and fruit yield in both 0.5 and $1 \mathrm{~m}$ lure heights. 
Table 1. Efficacy of pheromone trap in catching eggplant fruit and shoot borer, Leucinodes orbonalis male moths in four fields of Rajshahi.

\begin{tabular}{|c|c|c|c|c|c|}
\hline \multirow{2}{*}{ No. of observation } & \multicolumn{5}{|c|}{ Average No. of male ESFB moths catch/trap } \\
\hline & Field 1 & Field 2 & & Field 3 & Field 4 \\
\hline 1 & 2.5 & 8.2 & & 6.2 & 15.6 \\
\hline 2 & 3.6 & 7.0 & & 4.7 & 13.9 \\
\hline 3 & 4.2 & 9.0 & & 5.6 & 16.0 \\
\hline 4 & 1.8 & 10.5 & & 5.5 & 14.5 \\
\hline 5 & 2.7 & 8.7 & & 4.2 & 14.1 \\
\hline 6 & 3.8 & 7.8 & & 6.4 & 16.4 \\
\hline 7 & 4.5 & 9.5 & & 5.2 & 15.2 \\
\hline 8 & 3.6 & 7.2 & & 5.3 & 13.0 \\
\hline 9 & 1.7 & 9.6 & & 4.7 & 14.7 \\
\hline 10 & 4.2 & 7.4 & & 4.2 & 16.1 \\
\hline Total & 32.6 & 84.9 & & 52.0 & 149.5 \\
\hline Mean \pm S.E. & $3.26 \pm 0.32 a$ & $8.49 \pm 0.36 c$ & & $5.20 \pm 0.24 b$ & $14.95 \pm 0.34 d$ \\
\hline \multicolumn{6}{|c|}{ ANOVA } \\
\hline Source of Variation & SS & df & MS & $\mathrm{F}$ & F crit \\
\hline Between Groups & 788.477 & 3 & 262.8257 & 251.521 & 2.8662 \\
\hline Within Groups & 37.618 & 32 & 1.044944 & $P<0.01$ & LSD 1.257 \\
\hline Total & 826.095 & 35 & & & \\
\hline
\end{tabular}

Table 2. Average moth catch, damaged shoot, fruit and yield due to mass installation of pheromone trap in eggplant.

\begin{tabular}{|c|c|c|c|c|c|c|c|c|}
\hline \multirow{2}{*}{ Treatment } & \multicolumn{2}{|c|}{ Average moth catch } & \multicolumn{2}{|c|}{ Damaged shoot (\%) } & \multicolumn{2}{|c|}{ Damaged fruit (\%) } & \multicolumn{2}{|c|}{ Fruit yield (q/ha) } \\
\hline & Lure $0.5 \mathrm{~m}$ & Lure $1.0 \mathrm{~m}$ & Lure $0.5 \mathrm{~m}$ & Lure $1.0 \mathrm{~m}$ & Lure $0.5 \mathrm{~m}$ & Lure $1.0 \mathrm{~m}$ & Lure $0.5 \mathrm{~m}$ & Lure $1.0 \mathrm{~m}$ \\
\hline & $1.76 \pm 0$ & $4.54 \pm 0.94$ & $19.34 \pm 2.31$ & - & $29.74 \pm 1.87$ & $14.47 \pm 2.19$ & $176.58 \pm 6.38$ & $232.56 \pm 6.63$ \\
\hline $\begin{array}{l}\text { No Trap installed } \\
\text { t- value }\end{array}$ & - & $P<0,01$ & $\begin{array}{r}34.59 \pm \\
P<0 .\end{array}$ & $\begin{array}{l}2.65 \\
01\end{array}$ & $\begin{aligned} 47.27 \pm \\
P<0\end{aligned}$ & \pm 2.38 & $\begin{array}{c}90.00 \\
P<\end{array}$ & \pm 3.21 \\
\hline
\end{tabular}

Table 3. Impact of IPM strategy on control of Leucinodes orbonalis in eggplant fields.

\begin{tabular}{lcccccc}
\hline \multirow{2}{*}{ Criteria of evaluation } & \multicolumn{3}{c}{ No trap operated } & \multicolumn{3}{c}{ Trap operated } \\
\cline { 2 - 6 } & $\begin{array}{c}\text { Non-IPM } \\
\text { Block }\end{array}$ & IPM Block & $\mathrm{t}$ & $\begin{array}{c}\text { Non-IPM } \\
\text { Block }\end{array}$ & IPM Block & $\mathrm{t}$ \\
\hline Moth catches/trap/week & - & - & - & 10.25 & 1.23 & $\mathrm{P}<0.01$ \\
Shoot damage (\%) & 3.48 & 1.56 & $\mathrm{P}<0.01$ & 1.12 & 0.81 & $\mathrm{P}<0.05$ \\
Fruit damage (\%) & 31.15 & 10.66 & $\mathrm{P}<0.01$ & 32.56 & 12.34 & $\mathrm{P}<0.01$ \\
Fruit yield $\left(\mathrm{kg} / 100 \mathrm{~m}^{2}\right)$ & 13.70 & 27.54 & $\mathrm{P}<0.01$ & 8.50 & 9.95 & $\mathrm{P}<0.01$ \\
\hline
\end{tabular}

Impact of IPM strategy on control: Impact of IPM strategy on control of ESFB in the pheromone trap operated and no trap operated fields are shown in Table 3. It was observed that when no trap was operated in the eggplant fields the shoot damage, fruit damage and fruit yield were $3.48 \%, 31.15 \%$ and $13.70 \mathrm{~kg} / 100 \mathrm{~m}^{2}$ in the non-blocks and they were $1.56 \%, 10.66 \%$ and $27.54 \mathrm{~kg} / 100 \mathrm{~m}^{2}$ in the IPM blocks respectively. In trap operated blocks the number of moth catches per trap, shoot damage, fruit damage and fruit yield were 10.25 , $1.12 \%, 32.56 \%$ and $8.50 \mathrm{~kg} / 100 \mathrm{~m}^{2}$ in the non-IPM operated blocks; whereas the values were $1.23,0.81 \%$, $12.34 \%$ and $9.95 \mathrm{~kg} / 100 \mathrm{~m}^{2}$ in the IPM operated blocks respectively.

\section{Discussion}

In a related study conducted at BARI (1999), the influence of different materials used to dispense the pheromone was studied. Sex pheromone, $3 \mathrm{mg}$, was dispensed in white rubber septa, polyethylene vials 
(wall thickness of $1.5 \mathrm{~m}$ ), or black rubber septa. Winged traps baited with individual dispensers were placed in the field for 24 nights and the numbers of ESFB male adults trapped were recorded daily. Polyethylene vials caught significantly more adults than either black or white septa (Cork et al., 2001). This information proved useful in economizing use of pheromone. For all subsequent studies, pheromone chemicals were dispensed in polyethylene vials rather than traditionally used rubber septa.

Results of trap catches from the four different locations varied considerably. This is more likely due to the varying sources of ESFB being trapped. If the insects are coming in from outside, which is usually but not exclusively the case in the initial stages of infestation, they are likely be flying well above the soil surface or even above crop canopy. In such cases, traps placed at a higher level, at or above crop canopy, are more likely to trap these insects. However, as the season progresses, substantial numbers of adults are likely to come from the pupae from local infestation. The adults emerging from such pupae are likely to be trapped in traps nearer to the soil. Basic studies at AVRDC (1999) revealed that neonate adults become sexually mature immediately, in some cases within an hour, after emergence from pupae starting at dusk. Since pupae emerge from the soil surface, the neonate adults could very well be below the plant canopy and the pheromone chemical has to be there to trap sexually matured males before mating. This phenomenon leaves the question of appropriate trap height in doubt.

In a series of tests, possible effects of minor component of ESFB sex pheromone, (E)-11-hexadecenyl alcohol (E11-16:OH), on sex pheromone related behavior and mating in both male and female adults was studied. In nature, E11-16:OH does not attract ESFB males at any concentration from 10 to $500 \mu \mathrm{g}$, whereas the major component (E)-11-hexadecenyl acetate (E11-16:Ac), alone attracts the insects, especially at higher concentrations. The addition of a mere 1\% of E11-16:OH, however, synergizes the effect of E11-16:Ac in attracting male ESFB moths at much lower pheromone concentrations. In all tests, 30 $\mathrm{gg}$ of E11-16:OH, which is equal to the amount of this chemical in standard $3 \mathrm{mg}$ of pheromone lure, was used. Zhu et al. (1987) identified (E)-11hexadecenyl acetate as the pheromone of $L$. orbonalis and reported that traps baited with 300 to $500 \mu \mathrm{g}$ attracted more male moths than six virgin females in a field test. Subsequently Attygalle et al. (1988) identified (E)-11hexadecen-1-ol in addition to the related acetate using insects obtained from Sri Lanka. In order to optimize the blend of the two compounds identified in the pheromone glands of $L$. orbonalis preliminary field trials were conducted in India. These showed that the addition of trace of (E)-11hexadecen-1-ol to (E)11hexadecenyl acetate increased trap catches significantly (Cork and Hall, 1998).

Among the four traps used by Cork et al. (2003) the open delta caught significantly greater numbers of ESFB males than other traps. Among those traps, only the water-trough trap can be fabricated locally when needed at an affordable price. All others have to be imported from abroad and were costly. Locally fabricated watertrough traps (BARI 1999) were used in the present investigation.

The optimal trap height determination is very much necessary. The traps placed at crop canopy level caught significantly more male moths than traps placed $0.5 \mathrm{~m}$ above or below the crop canopy in Bangladesh (Cork et al. 2003). In the present experiment lure height of $1 \mathrm{~m}$ from the ground was found to be effective in catching male moths. The traps should be erected at every $10 \mathrm{~m}$ or less for effective attraction (Prasad et al. 2005). In general, it has been suggested to place the traps at a density of 100 per ha (Cork et al. 2003). Thus, the ESFB sex pheromone traps as a component of IPM significantly reduced the fruit damage and increased the yield in South Asia (Alam et al. 2003, Cork et al. 2003).

\section{Conclusions}

The broad-spectrum chemical pesticides sprayed to kill the fruit borer larvae will also kill the beneficial insects. This is the biggest disadvantage of the use of pesticides in combating fruit borer. Pheromones undoubtedly have an important role to play in insect pest management programmes in Bangladesh. The 
pheromone of fruit and shoot borer moth is now synthesized and produced in the factory. It is available in the market and to use the sex pheromone in the field, one needs two items: the chemical (or the pheromone) lure and a suitable trap, which are available in Bangladesh with much cost effective price. Thus pheromonal control as an IPM strategy may control ESFB with minimal use of pesticides.

\section{References}

Alam AZ, Sana DL. 1964. Biology of Leucinodes orbonalis Guenee in East Pakistan. In: Review of Research, Division of Entomology, 1947-64. Dhaka: Agriculture Information Service, Department of Agriculture, 192-200p.

Alam SN, Rashid MA, Rouf FMA, Jhala RC, Patel JR, Satpathy S, Shivalingaswamy TM, Rai S, Wahundeniya I, Cork A, Ammaranan C, Talekar NS. 2003. Development of an integrated pest management strategy for eggplant fruit and shoot borer in South Asia. Technical Bulletin 28, AVRDC - The World Vegetable Center, Shanhua, Taiwan, 66 pp.

Ali MI, Ali MS, Rahman MS. 1980. Field observation of wilt disease and shoot and fruit borer attack on different cultivars of brinjal. Bangladesh J Agril Sci 7, 193-194.

Allam MA, Rao PK, Rao BHK, 1982. Chemical control of brinjal shoot and fruit borer, Leucinodes orbonalis Guen. with newer insecticides. Entomon 7, 133-135.

Attygalle AB, Schwarz J, Gunawardena NE. 1988. Sex pheromone of brinjal shoot and pod borer Leucinodes orbonalis Guénee (Lepidoptera: Pyralidae: Pyraustinae). Z. Naturforsch, 43C: 790-792.

AVRDC. 1999. AVRDC Report 1998. AVRDC Publication No. 99-492. Shanhua, Taiwan: Asian Vegetable Research and Development Center, 148pp.

BARI (Bangladesh Agricultural Research Institute). 1999. Annual report 1998-99. Joydebpur, Gazipur, Bangladesh: BARI. 481pp.

Cork A, Hall DR. 1998. Application of pheromones for crop pest managementin the Indian sub-continent. J Asia-Pacific Entomol 1, 3549. http://dx.doi:10.1016/S1226-8615(08)60005-9

Cork A, Alam SN, Das A, Das CS, Ghosh GC, Farman DI, Hall DR, Maslen NR, Vedham K, Phythiam SJ, Rouf FMA, Srinivasan K. 2001. Female sex pheromone of brinjal fruit and shoot borer, Leucinodes orbonalis blend optimization. J Chem Ecol 27(9), 1867-1877. http://dx.doi:10.1023/A:1010416927282.PMid:11545376

Cork A, Alam SN, Rouf FMA, Talekar NS. 2003. Female pheromone of brinjal fruit and shoot borer, Leucinodes orbonalis: trap optimization and preliminary mass trapping trials. Bull Entomol Res 93, 107-113. http://dx.doi:10.1079/BER2002220 PMid:12699531.

Dhandapani N, Shelkar UR, Murugan M. 2003. Bio-intensive pest management in major vegetable crops: An Indian perspective. J Food Agri Environ 1(2), 330-339.

FAO (Food and Agricultural organization). 2003. Inter country programme for integrated pest management in vegetables in South and South-East Asia. Eggplant integrated pest management: An ecological guide. Rome, Italy, 177pp.

FAO. 2007. FAOSTAT data 2005. http://www.fao.org (accessed on 28 January 2011).

Gunawardena NE, Attygalle AB, Herath HMWKB. 1989. The sex pheromone of the brinjal pest, Leucinodes orbonalis Guenee (Lepidoptera): problems and perspectives. J Nat Sci Council, Sri Lanka, 17(2), 161-171.

Islam MN, Karim MA. 1991. Management of the brinjal shoot and fruit borer, Leucinodes orbonalis Guen, (Lepidoptera: Pyralidae) in field. In: Annual Research Report 1990-91, Entomology Division, Bangladesh Agriculture Research Institute, Joydebpur, Gazipur, 44 - 46pp.

Kabir KH, Baksh ME, Rouf FMA, Ahmed A. 1996. Insecticide use pattern on vegetables at farmer's level of Jessore region in Bangladesh. Bangladesh J Agric Res 21(2), 214-254.

Kalloo G. 1988. Biochemical basis of insect resistance in vegetables. Vegetable Breeding (Vol. II), CRC Press Inc Boca Raton, Florida.

Krishnaiah K. 1980. Assessment of crop losses due to pests and diseases. In: Govindu HC (ed), University of Agricultural Sciences Technology Series 33, pp. 259-267, Bangalore.

Kuppuswamy S, Balasubramanian M. 1980. Efficacy of synthetic pyrethroids against brinjal fruit borer, Leucinodes orbonalis Guen. $S$ Indian Hort 28(3), 91-93.

Maleque MA, Islam MN, Kundu R, Islam MS. 1998. Judicious use of insecticides for the management of the brinjal shoot and fruit borer. Bangladesh J Entomol 8, 97-107.

Prasad H, Singh HM, Singh AK. 2005. Effective range of sex pheromone of Leucinodes orbonalis Guen. J Appl Zool Res 16(1), 81-82. 
Purohit ML, Khatri AK. 1973. Note on the chemical control of Leucinodes orbonalis (Guen) (Lepidoptera: Pyraustidae) on brinjal. Indian J Agric Sci 43, 214-215.

Rashid MA, Alam SN, Rouf FMA, Talekar NS. 2003. Socio-economic parameters of eggplant protection in Jessore District of Bangladesh. Technical Bulletin 29. AVRDC - The World Vegetable Center, Shanhua, Taiwan, 37pp.

Rashid MM. 1999. Begun Paribarer Shabji. In: Shabji Biggan (in Bengali) 2nd edn. Rashid Publishing House, 94 Old DOHS, Dhaka1206.

Sasikala K, Rao PA, Krishnayya PV. 1999. Comparative efficacy of eco-friendly methods involving egg parasitoid, Trichogramma japonicum, mechanical control and safe chemicals against Leucinodes orbonalis Guenee infesting brinjal. J Entomol Res 23, 369-372.

Zhu P, Kong F, Yu S, Yu Y, Jin S, Hu X, Xu J. 1987. Identification of the sex pheromone of eggplant borer Leucinodes orbonalis Guénee (Lepidoptera: Pyralidae). Zeitschrift fuer Naturforschung 42, 1347-1348. 